\title{
Mobile communication for intellectually challenged people: a proposed set of requirements for interface design on touch screen devices
}

Zelai Saenz de Urturi Breton, Fernando Jorge Hernández, Amaia Méndez Zorrilla and Begoña García Zapirain

\author{
* Correspondence: amaia. \\ mendez@deusto.es \\ DeustoTech Institute of \\ Technology, DeustoTech-LIFE Unit. \\ University of Deusto, Avda. \\ Universidades 24, 48007 Bilbao, \\ Spain
}

\begin{abstract}
The use of certain applications for touch-based mobile devices can prove to be difficult for intellectually challenged people. By performing tests and gathering user feedback, great difficulty has been detected in the use of various applications due to their complicated interfaces.

The authors propose a set of guidelines, aimed at developers, to help design more accessible interfaces when developing applications for intellectually challenged, so this might increase the overall ease of use of mobile devices.
\end{abstract}

\section{Introduction}

Mobile phones have become an unmissable tool in society's everyday life. According to the study published by Telefonica (European broadband and telecommunications company) [1], nearly $74 \%$ of people with an intellectual disability aged $15-64$ own or use a mobile phone.

Additionally the number of touch-enabled smartphone devices has increased considerably in recent years [2], as well as the number of existing applications for operating systems.

When developers create a new application, it usually follows the basic rules of user interface design, which sometimes implies an accessibility problem, especially for people with intellectual disabilities, due to some specific designs.

An Intellectual disability is a broad concept encompassing various intellectual deficits, i.e. individuals who are mentally challenged [3], have specific learning disabilities or suffer from problems acquired later in life through sustained brain injuries or neurodegenerative diseases like dementia [4].

Most individuals with Down Syndrome (DS) or Asperger Syndrome (AS) also have an intellectual disability [5,6], such as reading or listening problems [7], and as a consequence, these groups may have additional limitations when it comes to interface interaction, which makes their use of a smartphone even more difficult. Users of this group have detected issues related to the mobile displays: buttons are too small causing them to push wrong numbers and letters frequently, non-user-friendly menu arrangement and unclear

(C) 2012 de Urturi Breton et al; licensee Springer. This is an Open Access article distributed under the terms of the Creative Commons Attribution License (http://creativecommons.org/licenses/by/2.0), which permits unrestricted use, distribution, and reproduction in any medium, provided the original work is properly cited. 
instructions on how to find and use some functions (such as: how to zoom in on the screen).

One possible cause of this problem might be due to the functional impairment experienced by the class of disabled mobile phone users. The nature of this problem is inherently complex and results in difficulty grasping the underlying problems, which in turn leads to a lack of understanding among mobile phone designers and developers.

One possible approach to the problems disabled mobile phone users experience is to add additional requirements to the development of mobile phones. The specific set of requirements needed can be found by involving intellectually challenged users in the design process starting at the requirement stage and ideally throughout the entire development phase as well. Some testing has been done to understand the problems related to their mobile phone use. Specifically, this article seeks to answer the following two research questions:

1. What are the difficulties that intellectually challenged people face when using mobile phones?

2. What are the characteristics of a disability-friendly mobile interface?

\section{Testing}

The users chosen by the experts to participate in the evaluation are 10 adults, both male and female. As users with AS or DS, the degree of intellectual disability for them is classified as being between moderate and mild disability according to the WHO (World Health Organization) [8].

Testing was performed in three sessions which lasted around 3 hours in a 'neutral' location. This was believed to be helpful for avoiding either negative or positive associations with a particular site or building: the meeting room of the FSDPV (Basque Country Down Syndrome's Association) and APNABI (Association of Parents of individuals with Autism in Bizkaia) associations.

To perform the test, three smartphones and two tablets (with 7" and 10" screens) were used and the results were obtained after observing the interaction of the participants with a sequence set of applications developed by the experts [9], Google Maps and a text-filled screen, i.e. SMS (Short Message Service).

\section{Problems experienced}

Combining experts' observations, opinions and experiences, the problems intellectually challenged users might experience when using touch screen mobile phones are illustrated in the Table 1.

\section{Characteristics of a disability mobile interface}

The proposed set of requirements is described below:

- Eliminate non-essential images/buttons/functions: Be critical of the purpose of any image/button/function. Is it just there purely for aesthetic purposes or does it convey a practical one?

- Components like images, buttons or text boxes must be of a suitable size so that they can be easily seen or pressed, e.g. the keyboard display size. 
Table 1 Problems experienced

\begin{tabular}{ll}
\hline Item & Problem \\
\hline Buttons & $\begin{array}{l}\text { Some are too small, do not click when pressed and therefore provide no feedback to whether } \\
\text { or not the associated number had been dialled or pressed. }\end{array}$ \\
Menus & Too many, most of them unnecessary, difficult to understand and recall. \\
Text size & Too small to read (even with corrective lenses). \\
Touch & $\begin{array}{l}\text { When interacting with a tactile component, the user presses on the component and waits until } \\
\text { screens }\end{array}$ \\
& $\begin{array}{l}\text { some feedback is received, instructing them how to proceed or to remove their finger from the } \\
\text { screen. } \\
\text { In other cases, if two components need to be pressed, one after other, (for instance when } \\
\text { introducing text) the finger is not retracted to interact with both, but is dragged across the } \\
\text { screen until the second component is reached. } \\
\text { Multi-Touch events: Users are unable to instinctively use the gestures required to zoom, however } \\
\text { given sufficient assistance they can learn to generate the required finger movements. }\end{array}$ \\
\hline
\end{tabular}

- Added voice output for available menus for those with reduced vision.

-When it comes to interacting with other interface components, such as scrollbars, lists, etc., it is convenient to use other alternative feedback mechanisms like device vibration or sounds that vary in intensity as a sign that the interface is being adapted. Users can therefore sense any adaptation more easily.

- If two components need to be pressed, a message could be displayed telling the user to press the screen again.

- When explaining how use the zoom characteristic, it could be necessary to provide an explanation in the form of an alert dialogue.

When designing interfaces for intellectually challenged people, developers should not assume that these users have the same preferences as most people. The main characteristic that should be taken into account is that the interface should be clear and concise. In these cases, the simpler the better is good rule of thumb.

\section{Conclusions}

In conclusion, this research contributed to a better understanding of intellectually challenged people while interacting with touch-based mobile devices. The mismatch between these users and design mental models produced the hindrance of using mobile phones. The requirements presented should help inclusive industrial designers to understand the erroneous stereotypes of mobile phones and their exclusions of intellectually challenged customers. Therefore, any application with an interface designed following the described requirements can fulfill its function and, at the same time, be more accessible for the intellectual challenged. This article offers a possible effective list of recommendations for intellectually challenged people who want to use a smartphone and its applications to improve their daily life.

\footnotetext{
Acknowledgements

This work was partially supported by the Basque Country Department of Education, Universities and Research. The authors also want to thank the cooperation of disabled associations: FSDPV and APNABI.

Received: 8 January 2012 Accepted: 1 February 2012 Published: 1 February 2012

\section{References}

1. Use of Mobile Telephony by Disabled People in Spain. [http://www.tendencias21.net/telefonica/El-90-por-ciento-delas-personas-con-discapacidad-utiliza-habitualmente-el-telefono-movil_a7.html].

2. Global mobile sales: 94 million smartphones sold (2011). [http://www.celularis.com/mercado/ventas-moviles-globales94-millones-smartphones.php].
} 
3. NICHCY: National Dissemination Center for Children with Disabilities. [http://nichcy.org/disability/specific/intellectual].

4. Strydom A, Romeo R, Perez-Achiaga N, Livingston G, King M, Knapp M, Hassiotis A: Service use and cost of mental disorder in older adults with intellectual disability. The British Journal of Psychiatry 2010, 133-138.

5. Næsa BKari-Anne, Melby-Lervåga Monica, Hulmea Charles, Lystera Halaas Solveig-Alma: Reading skills in children with Down syndrome: A meta-analytic review. Research in Developmental Disabilities 2011.

6. Fernández-Jaén A, Martín Fernández-Mayoralas D, Calleja-Pérez B, Muñoz Jareño N: Síndrome de Asperger: Diagnóstico y tratamiento. Rev NEUROL 2007, 44.

7. Esbensen JAnna: Health conditions associated with aging and end of life of adults with Down syndrome. Rev Res Ment Retard 2010, 39:107-126.

8. World Health Organization. [http://www.who.int/en/index.html].

9. de Urturi ZS, Zorrilla AM, Zapirain BG: Serious Game based on first aid education for individuals with Autism Spectrum Disorder (ASD) using android mobile devices. Computer Games (CGAMES), 16th International Conference 2011, 223-227.

doi:10.1186/2192-1121-1-1

Cite this article as: de Urturi Breton et al: Mobile communication for intellectually challenged people: a proposed set of requirements for interface design on touch screen devices. Communications in Mobile Computing 2012 1:1.

\section{Submit your manuscript to a SpringerOpen ${ }^{\circ}$} journal and benefit from:

- Convenient online submission

- Rigorous peer review

- Immediate publication on acceptance

- Open access: articles freely available online

- High visibility within the field

- Retaining the copyright to your article

Submit your next manuscript at $\boldsymbol{~ s p r i n g e r o p e n . c o m ~}$ 